\title{
Science Literacy: A Discussion and an Information-based Definition
}

\section{Gregg Sapp}

\begin{abstract}
Recently, science literacy has been the subject of much discussion in both the scholarly and popular press. The concept of science literacy encompasses two distinct but related dimensions: the first being concerns for the quality of scientific and technical education that American students receive at all levels, and the second being deficiencies and misconceptions that exist in the overall public understanding of science. Several definitions of science literacy identify the ability to find and to use appropriate information as being a fundamental characteristic of a scientifically literate individual. Building upon this idea, this article suggests that librarians - information experts - could play a significant role in the promotion of science literacy and recommends ways by which this might be accomplished.
\end{abstract}

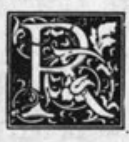

ecently, critics in the popular, professional, and scholarly press alike have expressed concern regarding America's lack of "science literacy." Poor science literacy begins with the science education that children receive in grade school, then continues into college, where decreasing numbers of students choose to seek degrees in science and engineering (S/E), and finally results in an adult public that lacks a basic understanding of the science and technology that affects them daily as citizens and consumers. The need to improve America's science literacy has been cited by some as critical for a modern, democratic nation that wishes to remain economically competitive in a high-tech world. ${ }^{1}$ While the popular press has put science literacy in the news, and while it has also been studied and editorialized in the literature of various academic disciplines, scarcely a footnote has appeared in recent library literature.
This article reviews and describes the current crisis in science literacy and formulates an information-based definition of the term. In a very real sense, science is a process of information discovery, dissemination, application (or analysis), and retrieval. A person cannot be scientifically literate and informationally illiterate. All of this suggests that librarians-information experts-could have a vital role in the promotion of science literacy in America.

\section{DIMENSIONS OF SCIENCE LITERACY}

Science literacy has two distinct dimensions. The first relates to education, in which the concern is that U.S. students at all levels are comparatively deficient in the sciences to students in other countries. In his 1990 state of the union address, President George Bush optimistically proclaimed his goal that "by the year 2000 , U.S. students must be first in the world in math and science achievement." 2 Before this objective can be real-

Gregg Sapp is Head of Access Services, Roland R. Renne Library, Montana State University, Bozeman, Montana 59717. 
ized, however, some startling trends must be reversed. The entrenched problems in science education were the subject of a recent Newsweek feature, which asserted that "American science education serves not to nurture children's natural curiosity but to extinguish it with catalogs of dreary facts and terms." ${ }^{3}$ A 1988 report comparing science achievement in seventeen countries ranked the United States near the foot of the class in five out of five age groups, consistently behind such countries as Japan, Sweden, Singapore, Hungary, Australia, and Poland. ${ }^{4}$ Another area of particular concern is the dearth of American women and minorities in S/E. These groups consistently score below white males on SAT scores in technical sections and are approximately half as likely to seek a baccalaureate degree in S/E. ${ }^{5}$

The American public's understanding of science has been characterized as "deplorably low."

The number of college students majoring in S/E has been on the decline. Between 1966 and 1988, the percentage of college freshmen intending to major in mathematics dropped by half, from 12 percent to 6 percent. $^{6}$ In 1986, just 24 percent of entering freshmen declared their intention to major in $S / E$, down 3 percent from 1978, and fewer than half of these successfully complete a B.S. degree (the defection rate in physics, for example, is 40 percent). ${ }^{7}$ Some educators refer to a science "pipeline," which is broad at the top, where students enter the educational system, but which narrows over the years as students abandon science studies, then finally chokes off to a mere trickle at more advanced levels of accomplishment. ${ }^{8}$ In all, of the four million high school sophomores who entered the pipeline in 1977 , just $9,700(0.2$ percent) have earned or will have earned by the year 1992 a Ph.D. in a scientific or technical field.

Evidence shows that the numbers of students making it through the pipeline during this period may not be sufficient to meet projected industry demand. Currently, U.S. industry depends on new $\mathrm{S} / \mathrm{E}$ graduates to fill 45 percent of vacant positions. ${ }^{9}$ This dependency is likely to increase because of a "graying" of those employed in S/E. In 1987, 34 percent of all professional scientists and 41 percent of engineers were over fifty years old. Privately employed scientists and engineers are generally younger than those in academe. ${ }^{10}$ Women and minorities are underrepresented in the work force, as they are in undergraduate programs. Approximately 13 percent of theS/E work force are women, and just 2 percent are black."

The second dimension of science literacy reflects the problems that occur when scientifically undereducated children become adults. The American public's understanding of science has been characterized as "deplorably low" by the director of the Public Opinions Laboratory at Northern Illinois University, Jon D. Miller, who has conducted the most thorough surveys of the science literacy of adult Americans. ${ }^{12}$ Miller conducted his first survey, commissioned by the National Science Foundation, in 1979. ${ }^{13}$ Since that time, there has been little overall improvement. For example, in 1979 Miller found that about 22 percent of adult Americans knew what DNA is; a subsequent survey in 1987 found that 16 percent did. ${ }^{14}$ Only 45 percent of Americans today know that the Earth revolves around the sun; fewer than half of the population believe in evolution. Further, the pseudosciences are more popular than ever: 39 percent of Americans would characterize astrology as a science. Finally, the image of scientists themselves is somewhat tainted: 53 percent of Americans believe that, because of their esoteric knowledge, scientists possess "dangerous powers." In his analysis of these figures, Miller estimates that a mere 5 percent of the adult American population are science literate, which he defines as those people "possessing a reasonable vocabulary of scientific and technical terms."15

Even if reforms are made in American education and President Bush's goal is 
realized by the year 2000 , the beneficiaries of these reforms will not become decision makers for another ten to twenty years. Is the country fated to have a scientifically illiterate population until these generations mature? In recent years, scientists from various disciplines have called for active and organized efforts to promote science education and public understanding of science. Increasingly, scientists are speaking to the public, appearing in the media, and writing for general readers. Additionally, new programs to foster an awareness and appreciation of science have been designed by various institutions and scientific organizations. The message in these efforts is that science literacy is a national priority. Librarians can play a role in promoting science education and literacy. Miller, along with co-authors Robert Suchner and Alan Voelker, notes in the book Citizenship in an Age of Science that a pattern of regular information acquisition is essential for developing and maintaining science literacy. ${ }^{16}$ Librarians should strive to provide the bibliographic and reference services by which clients can keep up with important scientific developments and make sense of the big picture.

\section{A BRIEF HISTORY OF SCIENCE LITERACY}

In the early seventeenth century, any educated person could keep up with and comprehend virtually all published scientific treatises of the era. ${ }^{17}$ The full range of science was generically called "natural science," and it subsumed all disciplines and specialties. By the turn of the century, however, several trends and developments had begun to erode the inclusiveness of this monolithic natural science. As a result of these developments, which have continued to this day and are at the root of contemporary deficiencies in science literacy, scientists began to work and communicate in specialized arenas that are less and less approachable to the general public.

In his three-volume classic on the history of science, René Taton writes of the seventeenth-century revolution: "In less than a century-from William Gilbert's
De Magnete to Sir Isaac Newton's Principia - the face of science had changed almost beyond recognition." ${ }^{18}$ This century included such giants of science as Johann Kepler, Galileo, René Descartes, Francis Bacon, and Newton, whose various works challenged the authority of many ideas that had gone unquestioned since the Greeks. By questioning, these scientists encouraged the development of what is now called the "scientific method." Another factor that contributed to this revolution in science was the development of new technologies, such as the telescope, pioneered by Galileo, and the microscope, by Anthony van Leeuwenhoek. Finally, advances in mathematics, especially Newton's calculus, were leading increasingly and inevitably toward its adoption as the "language" of science. Galileo proclaimed, "Nature is written in mathematical language." ${ }^{\prime 19}$ All of these developments created barriers between science and public understanding. In Newton's lifetime, popularized accounts of his theories were created for those who could not understand the original work.

\section{Librarians should strive to provide the bibliographic and reference ser- vices by which clients can keep up with important scientific developments.}

With specialization, communication among scientists became much more of an esoteric process. Professional scientific societies were established, and, in them, scientists could meet and discuss issues with their elite circle of peers. The British Royal Society, for example, was founded in $16600^{20}$ The scientific journal-a format designed for currency and specialization-emerged as the primary vehicle for conveying the results of new research..$^{21}$ Within these journals, such as the Royal Society's Philosophical Transactions (1665), writing was technical, often mathematical, and aimed at an audience of specialists, rather than a general, educated public. The increasing numbers of journals published paralleled increases 
in the research being done, a harbinger of today's "information explosion." In the early eighteenth century, in order to assist scientists in their efforts to keep up with the literature, the first indexes and review publications appeared. ${ }^{22}$

Still, throughout the eighteenth and into the nineteenth century, much science remained intelligible to lay people. Charles Darwin, for instance, wrote On the Origin of Species with the intent that it should be read by biologists and nonbiologists alike. ${ }^{23}$ The early eighteenth century was an era when armchair scientists still made major contributions in observational sciences, such as biology and earth sciences, but had for the most part abandoned laboratory sciences such as physics and chemistry. ${ }^{24}$ Thus, popularizers appeared, such as Mary Somerville, who wrote the widely read On the Connexion of the Physical Sciences (1846). ${ }^{25}$ Further, several scientists were themselves active popularizers. Michael Faraday, for example, performed a series of public lectures titled "The Chemistry of the Candle."26

In America, where, by the mid-nineteenth century, there had developed a strong sense of science nationalism, science was viewed as being synonymous with progress. In the interest of furthering progress, efforts to popularize science were launched in order to debunk the misconceptions and superstitions that impeded it. ${ }^{27}$ The venerable Scientific American was first published in 1845 . In contrast to this magazine, in which the contributors were themselves scientists or technical specialists, much popularization was done by journalists, educators, and civic leaders who lacked any detailed background in science. This phenomenon is the subject of John Burnham's study How Superstition Won and Science Lost, in which he argues that, as science popularization drifted into the domain of these nonspecialists, the forces of "dilution" and "trivialization" undermined the original intent of popularization-to correct superstition. ${ }^{28}$

In the twentieth century, science popularization was conveyed in an ever-increasing variety of popular media. The first specialist science correspondents appeared in the 1920s and 1930s. Marcel LaFollette's Making Science Our Own describes in detail the content of science features published in general interest magazines and, in doing so, demonstrates how many contemporary images of science were formed. ${ }^{29}$ Science fiction emerged as a distinct genre and, in part because of its voracious popularity and in part because of the lack of information from more informed sources, contributed to the public's perception of what modern science could and could not do. ${ }^{30} \mathrm{Technol}-$ ogy created numerous new vehicles for popularization, such as radio, motion pictures, and, later, television.

The public regards scientists as a group of latter-day Sadduceean priests endowed with esoteric knowledge and decision-making authority.

In the immediate post-World War II era, the new science of nuclear physics, which abundantly displayed its potency at Hiroshima, stimulated a broad, media-based wave of popularization. Many of the popular images of science contained contradictions. On the one hand, the accomplishments of the Manhattan Project were depicted as a heroic triumph, which led not only to the end of the war, but also opened the door to the utopian technology of atomic power. On the other hand, the image of scientists suffered from the public's perception that, by having meddled in the affairs of God, they had unleashed a horrible force upon the world. ${ }^{31}$ The persisting popular image of Albert Einstein displayed this paradox: he was at once widely admired for his genius and simultaneously incorrectly faulted for having unwittingly set into motion the chain of events that led to the bomb. ${ }^{32}$ The time lent itself to wild speculation and fears, and these were expressed in all varieties of popular media.

In The New Priesthood (1965), Ralph Lapp identified, for perhaps the first time, the potential danger to American democracy of a situation in which the 
general public lacks a basic understanding of science. The public regards scientists as a group of latter-day Sadduceean priests endowed with esoteric knowledge and decision-making authority. ${ }^{33}$ Lapp addressed perceived conditions in an era when, despite the Sputnik-inspired national crusade to train competitive scientists and to reassert America's scientific ascendancy, the general public's knowledge of science was lacking.

Librarians can significantly influence America's crusade to improve science education.

More recently, the commercial enterprise of science popularization has seen some ups and downs. The apex of the "boom" cycle might have been in the late 1970 s and early 1980 s with the inception of twenty new general science magazines (including such titles as Omni, Discover, Science 80, and a revamped Science Digest), seventeen new television shows (including "Nova," "Omni," "Walter Cronkite's Universe," and such PBS specials as "Cosmos" and "The Ascent of Man"), and more than sixty newspaper sections dedicated to popular science. ${ }^{34}$ A Time magazine cover story on Cosmos creator Carl Sagan declared that "ennui" about popular science "has turned into enthusiasm." ${ }^{35}$ Former Fermilab director Robert Wilson called popularizations the "new literature of science" that would integrate a "technology of humanism into a common culture." 36 Some of these ventures were short-lived"Walter Cronkite's Universe" and Science 86 both folded in 1986- because of market saturation and lack of advertising revenue. Nevertheless, if science popularization did not emerge as a blockbuster industry, it did prove that it can attract and sustain an audience. ${ }^{37}$

Recognizing how science is perceived by the general public is essential for understanding why America's science literacy is low and why so many students eschew science studies. The general public acquires meaningful information (or misinformation) about science through various media. Invariably, whenever professional scientists speak of the need to improve science literacy, they call for increased and better popularization. Thus, America's science literacy can only be as good as the quality of the information that is available and the means by which it is sought and used. This idea lends itself to an information-based definition of science literacy.

Science literacy is built on a foundation of information; it is the result of successful, specialized informationseeking behavior. While many definitions are lengthy and multifaceted, this brief definition may serve for the present purpose: Science literacy is an active understanding of scientific methods and of the social and economic roles of science as they are conveyed through various media and is thus built on an ability to acquire, update, and use relevant information about science.

\section{DEFINITIONS OF SCIENCE LITERACY}

Science literacy is much less a measurement of technical knowledge than of science awareness. A person can know virtually nothing about quantum physics and still be scientifically literate. Some basic knowledge of fundamental scientific and technical concepts is characteristic of the scientifically literate person, but more vital is an awareness of how science affects our lives, an understanding of scientific methodology, and an ability to obtain and use information about science. Literacy, in this sense, does not mean the ability to read scientific jargon or mathematical notation, but rather means an ability to "follow scientists and engineers through society"; i.e., to perceive how technology affects us individually and societally. ${ }^{38}$ Science literacy also has an essentially participative and democratic aspect. Historian of science Michael Shortland writes, "In a word, to become scientifically literate is to become an active and effective citizen." 39

Science literacy can be best defined by the attributes and attitudes of those who possess it. It is cultivated rather than learned. Shortland cites the following as 
"components" of science literacy:

- An appreciation of the nature and aims of science and technology, including their historical origins and the epistemological and practical values which they embody.

- A knowledge of the way in which science and technology actually work, including the funding of research, the conventions of scientific practice, and the application of new discoveries.

- A basic grasp of how to interpret numerical data, especially relating to probability and statistics.

- A general grounding in selected areas of science, including a number of key interdisciplinary areas.

- An appreciation of the interrelationships between science, technology and society, including the role of scientists and technicians as experts in society.

- An ability to update and acquire new scientific information in the future. ${ }^{40}$

A similar, multifaceted definition of science literacy appeared in a 1983 Daedalus article by A. B. Arons. ${ }^{41}$ Because the word "literacy" can incorrectly imply an ability to read technical literature, the term has been challenged. Kenneth Prewitt, president of the Social Sciences Research Council, prefers the term "science savvy," and writes of it: "My understanding of the scientifically savvy citizen is a person who understands how science and technology impinge upon public lives. Although this understanding would be enriched by substantive knowledge of science, it is not coterminous with it." ${ }^{\prime 42}$

Miller describes science literacy as occurring within an "attentive public," a "self-selected group that has a high level of interest in, and a functional knowledge about, a given issue area." ${ }^{43}$ The accompanying model, originally developed by G. A. Almond in 1950, depicts a stratified pyramid wherein the attentive public, which in this case is the science literate, occupies a block near the top of the pyramid, just below the decision makers and the policy leaders. ${ }^{44} \mathrm{~A}$ basic characteristic of the attentive public is its desire to seek information. Conversely, the nonattentive public, which in this case is the scientific illiterate, resides in the wide bottom half of the pyramid and is characterized as being either unwilling or unable to remain informed about issues and new developments.

Among the attentive public, Almond further distinguishes between those who are mobilized, who go beyond information seeking and attempt to influence policy, and the nonmobilized. The mobilized faction has characteristics of a group that British science policy analyst Maurice Goldsmith calls "science critics." ${ }^{\prime 45}$ These laypersons rely on various media to follow the progress of science and, by virtue of their informed understanding of science and public policy, function as critics of modern science in a manner analogous to literary critics. Goldsmith sees these critics as being instrumental in shaping public understanding and appreciation of science. A society without individuals capable of playing this role is unlikely to initiate educational reforms or to improve overall science literacy.

Finally, scientific information must be accessible and comprehensible in order to be useful. Science popularization has been suggested as a means by which to accomplish science literacy. In his book Innumeracy, John Allen Paulos, lamenting the widespread mathematical illiteracy in America, suggests that mathematicians have a responsibility to popularize. He writes: "Mathematicians who don't deign to communicate their subject to a wider audience are a little like multimillionaires who don't contribute anything to charity." ${ }^{146}$ Scientists are beginning to adopt this attitude. Several world-class scientists-including Stephen Hawking, Roger Penrose, Stephen Jay Gould, Steven Weinberg, Heinz Pagels, Richard Feynman, Freeman Dyson, Jane Goodall, Douglas Hofstadter, and Paul Davies-have all written technical books for general readers. Sigma Xi, the honorary scientific society, held an international symposium in 1988 on the subject of how scientists can work to improve public understanding of $\mathrm{S} / \mathrm{E}{ }^{47}$ In recent years, editorials supporting popularization have appeared in American Scientist, Environmental Sci- 
ence and Technology, Chemical and Engineering News, and American Journal of Physics. ${ }^{48}$ Increasingly, the scientific community is seeking to demystify science.

\section{LIBRARY ISSUES AND CONCERNS}

If information supplies the necessary infrastructure of science literacy, then, clearly, librarians, as information experts and gatekeepers, can significantly influence America's crusade to improve science education and to enhance the overall public understanding of science. In one of the few recent library articles on this subject, Beth Clewis writes:

Scientific literacy research offers an opportunity for librarians to collect data of use and interest to other fields, especially communications and education. At its most ambitious, such research can contribute to cross-disciplinary discourse, and in doing so accomplish the dual goal of providing a theoretical basis for library policy and opening up library research to a wider audience. ${ }^{49}$

One area in which the library profession can lend its expertise is in fashioning a better understanding of the information-seeking behavior of scienceliterate individuals. Where and how is this information acquired? What factors inspire the information-seeking behavior? What media are preferred? How can access to relevant information be enhanced through library services? Library user studies may provide models that can be applied to the study of this specialized form of information-seeking behavior.

Another area in which librarians would be well qualified to contribute to existing research is in drawing composites of the characteristics of scientifically literate individuals. What are the origins of science literacy? It is known, for example, that a college education is one strong predictor of science literacy, and programs have been designed to exploit this connection. ${ }^{50}$ However, questions remain to be studied. Does this connection exist because these individuals learn basic science concepts in college, or, rather, is it that people who go to college simply have a greater predilection toward remaining informed? What factors affect the reten- tion of scientific information? Since many of the survey instruments used to gauge science literacy have been criticized because they test knowledge of facts rather than the ability to find information, librarians can bring to the debate an insight that could redefine the very means by which science literacy is measured. ${ }^{51}$

\section{Librarians whose academic back- grounds tend to be in the humanities and social sciences cannot afford to be "blinded" by science.}

Librarians must also be able to evaluate and apply the appropriate information resources. In a 1949 article published in Illinois Libraries, J. L. Crammer underscores the connection between science education and literacy and science popularizations. He writes:

But to make use of it (technology) demands not merely a few scientists, but a crowd of trained technicians who can work the factory processes and the techniques of modern agriculture, and a population of farmers willing to accept new agricultural methods and of citizens willing to live the industrial life. Popularization, therefore, may prepare the country as a whole for these scientific changes, but even more important is its job to attract recruits for training as technicians and scientists. ${ }^{52}$

Crammer urges librarians to learn the difference between good and bad popularizations and to apply these principles properly to bibliographic, collection development, and reference services. Today, this injunction needs to be repeated. In a 1982 article, Miriam Pollet writes: "As long as a fast buck can be made on the human need for explanation, mystery, and fantasy - a lay fascination with the 'brave new world' that can be hustled by the media-librarians had better be wary." ${ }^{53}$ Certainly, the publication of sensationalized books on topics ranging from the environment to the extinction of the dinosaurs warrants selective acquisitions. 
Several secondary sources provide reviews of and bibliographic access to new science popularizations. Many are already familiar to librarians: Science and Technology Books and Films (which, with the November/December 1989 issue began referring to itself as "the journal of science literacy"), Library Journal's annual "Best Sci-Tech Books" bibliography (published in March), the New York Public Library's New Technical Books list, Technical Book Review Index, and General Science Index. Librarians could also benefit from delving into the primary review sources in professional and specialized journals, such as those found in Science, Nature, Physics Today, BioScience, American Mathematical Monthly, Earth Science Reviews, Journal of the American Chemical Society, and American Scientist. Trends in professional journal literature are charted by the Institute of Scientific Information's Science Watch.

Finally, librarians, whose academic backgrounds tend to be in the humanities and social sciences, cannot afford to be "blinded" by science. Workshops and programs, such as that recommended by Tony Stankus for collection development issues related to science journals, can assist librarians without a science background in gaining facility with science information resources. ${ }^{54}$ To put it bluntly, scientifically illiterate librarians can do little to select materials and provide services that will contribute to making America the world leader in science literacy by the turn of the century. Last year, "information literacy" was ACRL's designated presidential theme. This important national priority continues to deserve attention and discussion.

\section{REFERENCES AND NOTES}

1. Louis Friedman and Tim Lynch, "Science as a National Priority," USA Today: The Magazine of the American Scene 118:47-48 (Sept. 1989).

2. George Bush, "Address before a Joint Session of Congress on the State of the Union, January 31, 1990," Compilation of U.S. Presidential Documents 26:146-51 (Feb. 5, 1990).

3. "Not Just for Nerds," Newsweek 115:52-64 (Apr. 9, 1990).

4. International Association for the Evaluation of Educational Achievement, Science Achievement in Seventeen Countries: A Preliminary Report (New York: Pergamon, 1988), p.25-55; "U.S. Students Near Foot of Class," Science 239:1237 (Mar. 1, 1988).

5. Jerilee Grandy, Ten Year Trends in SAT Scores and Other Characteristics of High School Seniors Taking the SAT and Planning to Study Thematics, Science, or Engineering (Princeton, N.J.: Educational Testing Service, 1985), p.1-28, tables passim; Congress of the United States, Office of Technology Assessment, Educating Scientists and Engineers: Grade School to Grad School (Washington, D.C.: Govt. Print. Off., Mar. 1989), p.32-36, 53.

6. Kenneth Green, "A Profile of Undergraduates in the Sciences," American Scientist 7:475-80 (Sept.-Oct. 1989).

7. Green, "A Profile of Undergraduates," passim; Office of Technology Assessment, Educating Scientists and Engineers p.48; Congress of the United States, Office of Technology Assessment, Higher Education for Science and Engineering (Washington, D.C.: Govt. Print. Off., 1989), p.39.

8. Office of Technology Assessment, Educating Scientists and Engineers" p.12; Sheila Widnall, "AAAS Presidential Lecture: Voices from the Pipeline," Science 241:1740-45 (Sept. 30, 1988).

9. For complete demographic trends in the S/E industry, see National Science Board, Science and Engineering Indicators-1989 (Washington, D.C.: Govt. Print. Off., 1989), p.62-84.

10. Ibid., p.59.

11. Ibid., p.62-84.

12. Jon D. Miller, "Scientific Literacy: An Empirical and Conceptual Review," Daedalus 112:29-48 (Spring 1983).

13. Jon D. Miller, K. Prewitt, and R. Pearson, The Attitude of the U.S. Public toward Science and Technology: A Report to the National Science Foundation (Chicago: National Opinion Research Ctr., 1980). Another interesting report for comparative purposes is British Royal Society, The Public Understanding of Science (London: Royal Society, 1985). 
14. Jon D. Miller, "The Scientifically Illiterates," American Demographics 9:26-31 (June 1987).

15. Jon D. Miller, "The Five Percent Problem," American Scientist 76:166 (Mar--Apr. 1988). Broken down more specifically, Miller finds that 3 percent of high school-educated individuals are scientifically literate, while 12 percent with college degrees are. Further, by Miller's definitions, just 18 percent of $\mathrm{Ph}$.D.s qualify.

16. Jon D. Miller, Robert Suchner, and Alan Voelker, Citizenship in an Age of Science (New York: Pergamon, 1980), p.93-99.

17. Jack Meadows, "The Growth of Science Popularization: A Historical Sketch," Impact of Science on Society 36:341-46 (Winter 1986).

18. René Taton, ed., History of Science: The Beginnings of Modern Science, from 1450 to 1800 (New York: Basic Books), p.393.

19. Ibid., p.186.

20. Michael Hunter, Establishing the New Science: The Experience of the Early Royal Society," (Woodbridge, Eng.: Boydell, 1989), p.1-27.

21. Ibid.

22. A. A. Marten, "Developments of European Scientific Journal Publishing before 1850," in Development of Science Publishing in Europe, ed. A. J. Meadows (Amsterdam: Elsevier, 1980), p.1-23.

23. Meadows, "The Growth of Science Popularization," passim.

24. Ibid.

25. Mary Somerville, On the Connexion of the Physical Sciences (New York: Arno, 1975). Reprint of the 1846 edition published by J. Murray, London.

26. Meadows, "The Growth of Science Popularization," passim.

27. Annette Woodlief, "Science," in Concise Histories of American Popular Culture, ed. Thomas Inge (Westport, Conn.: Greenwood, 1982), p.354-62; Oscar Handlin, "Science and Technology in Popular Culture," Daedalus 94:156-70 (Winter 1965); Matthew D. Whalen, "Science, the Public and American Culture," Journal of American Culture 4:14-25 (1981).

28. John Burnham, How Superstition Won and Science Lost: Popularizing Science and Health in the United States (New Brunswick, N.J.: Rutgers Univ. Pr.), p.226-62.

29. Marcell C. LaFollette, Making Science Our Own (Chicago: Univ. of Chicago Pr., 1990), passim.

30. Meadows, "The Growth of Science Popularization," p.341-46.

31. Paul Boyer, By the Bomb's Early Light: American Thought and Culture at the Dawn of the Atomic Age (New York: Pantheon, 1983), passim.

32. Alan J. Friedman and Carol C. Donley, Einstein in Myth and Muse (Cambridge, Mass.: Cambridge Univ. Pr., 1985), passim.

33. Ralph Lapp, The New Priesthood: The Scientific Elite and the Uses of Power (New York: Harper, 1965), passim.

34. Bruce V. Lewenstein, "Was There Really a Popular Science Boom?" Science Technology and Human Values 12:29-41 (Spring 1987).

35. "The Cosmic Explain," Time 116:62-69 (Oct. 20, 1980).

36. Robert Wilson, "The New Literature of Science," Bulletin of the Atomic Scientists 37:1-2 (Apr. 1981).

37. Bruce V. Lewenstein, "Why Isn't Popular Science More Popular?" American Scientist 76:447-49 (Sept.-Oct. 1988).

38. Bruno Latour, Science in Action (Cambridge, Mass.: Harvard Univ. Pr., 1987), p.15, passim.

39. Michael Shortland, "Advocating Science: Literacy and Public Understanding," Impact of Science on Society 152:305-16 (Fall 1988).

40. Ibid.

41. A. B. Arons, "Achieving Wider Science Literacy," Daedalus 112:91-122 (Spring 1983).

42. Kenneth Prewitt, "Civil Education and Science Illiteracy," Journal of Teacher Education 34:17-20 (Nov.-Dec. 1983).

43. Jon D. Miller, The American People and Science Policy (New York: Pergamon, 1983), p.33-55.

44. G. A. Almond, The American People and Foreign Policy (New York: Harcourt, 1950), p.226-42. 
45. Maurice Goldsmith, The Science Critic: A Critical Analysis of the Popular Presentation of Science (London: Rutledge and Kegan Paul, 1980), passim.

46. John Allen Paulos, Innumeracy: Mathematical Illiteracy and Its Consequences (New York: Hill \& Wang, 1988), p.80.

47. "Annual Meeting Hosts International Symposium on the Public Understanding of Science and Technology," American Scientist 77:12-15 (Jan.-Feb. 1989).

48. Roald Hoffman, "Plainly Speaking," American Scientist 75:418-20 (July-Aug. 1987); "Reporting on Science for the Public," Environmental Science and Technology 23:491 (Nov. 5, 1989); Edward Jefferson, "Communicating Science," Chemical and Engineering News 62:3 (Sept. 3, 1984); Carl Sagan, "Why Scientists Should Popularize Science," American Journal of Physics 57:295 (Apr. 1, 1989).

49. Beth Clewis, "Scientific Literacy: A Review of the Literature and Implications for Librarianship," Collection Management 12:101-12 (Fall 1990).

50. Miller, "The Scientifically Illiterates," passim; American Association for the Advancement of Science, The Liberal Art of Science (Washington, D.C.: American Assn. for the Advancement of Science), p.3-26.

51. Morris Shamos, "A False Alarm in Science Education," Issues in Science and Technology 4:65-69 (Spring 1988); Morris Shamos, "Scientific Literacy Where It Counts," Journal of College Science Teaching 14:196-97 (Feb. 1990). Shamos is probably the most prolific critic of the concept of science literacy.

52. J. L. Crammer, "The Popularization of Science through Cheap Books," Illinois Libraries 31:385-95 (Nov. 1949).

53. Miriam Pollet, "Criteria for Science Book Selection in Academic Libraries," Collection Building vol. 42-47 (Fall 1982).

54. Tony Stankus, "Building Confidence and Competence: A Workshop in Science Journals for Beginning Librarians without a Science Background," Serials Librarian 18:28-45 (Fall 1990).

\section{IN FORTHCOMING ISSUES OF \\ COLLEGE \& RESEARCH LIBRARIES}

The Emergence of Paraprofessionals in Academic Libraries: Perceptions and Realities Larry Oberg

Users' Reactions to CD-ROM: The Penn State Experience

Cindy Faries

The Process and Value of Self-Study in a Medium-Sized University Library

William L. Beck and Marsha L. Nolf

Online Catalog Failure as Reflected through Interlibrary Loan Error Requests

Scott Seaman

Reconciling Pragmatism, Equity, and Need in the Formula Allocation of Book and Serial Funds Charles Lowry

Selected Reference Books, 1991

Eileen Mcllvaine

Research Notes

The Economics of Economics Journals: A Statistical Analysis of Pricing Practices by Publishers H. Craig Petersen 